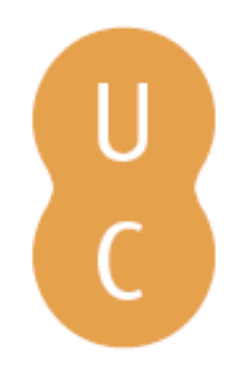

\title{
nombalina
}

\section{Gestão de informação na biblioteca digital especializada}

\author{
Autor(es): $\quad$ Mendes, Olga Bessa
}

Publicado por: Imprensa da Universidade de Coimbra

URL

persistente: URI:http://hdl.handle.net/10316.2/31935

DOI: $\quad$ DOI:http://dx.doi.org/10.14195/978-989-26-0869-3_27

Accessed : $\quad$ 26-Apr-2023 07:13:12

A navegação consulta e descarregamento dos títulos inseridos nas Bibliotecas Digitais UC Digitalis, UC Pombalina e UC Impactum, pressupõem a aceitação plena e sem reservas dos Termos e Condições de Uso destas Bibliotecas Digitais, disponíveis em https://digitalis.uc.pt/pt-pt/termos.

Conforme exposto nos referidos Termos e Condições de Uso, o descarregamento de títulos de acesso restrito requer uma licença válida de autorização devendo o utilizador aceder ao(s) documento(s) a partir de um endereço de IP da instituição detentora da supramencionada licença.

Ao utilizador é apenas permitido o descarregamento para uso pessoal, pelo que o emprego do(s) título(s) descarregado(s) para outro fim, designadamente comercial, carece de autorização do respetivo autor ou editor da obra.

Na medida em que todas as obras da UC Digitalis se encontram protegidas pelo Código do Direito de Autor e Direitos Conexos e demais legislação aplicável, toda a cópia, parcial ou total, deste documento, nos casos em que é legalmente admitida, deverá conter ou fazer-se acompanhar por este aviso.

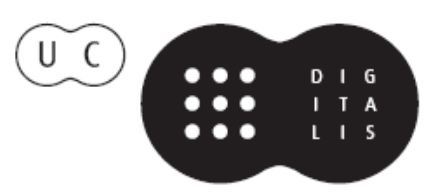


Maria Manuel Borges

Elias Sanz Casado

Coordenação

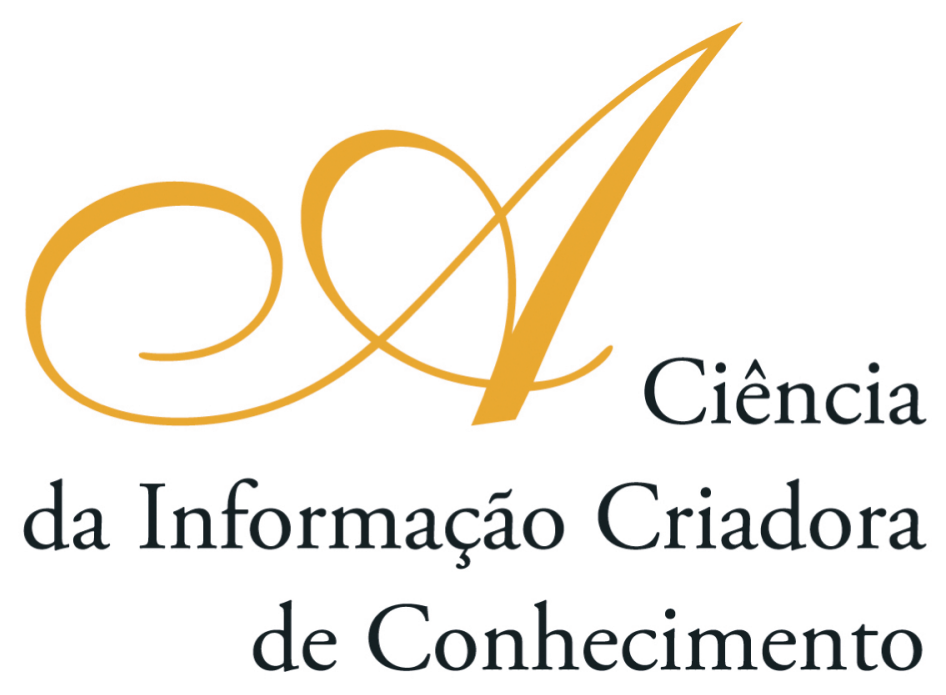

Vol. I I

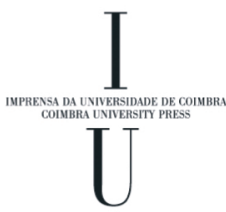

- COImbra 2009 


\title{
Gestão de informaÇão Na bibloteca digital especializada
}

\author{
Olga Bessa Mendes \\ Instituto Nacional de Estatística (Portugal)
}

\section{Resumo}

A biblioteca digital especializada acentua a necessidade do uso de terminologia de especialidade e de instrumentos de classificação que possibilitem estabelecer uma ponte desta terminologia para utilizadores especialistas e não-especialistas. A organização de conteúdos e a terminologia de acesso à informação constituem um obstáculo quer para o utilizador quer para o gestor de informação, por causa do volume e da diversidade da informaçáo. A terminologia científica e técnica desempenha, assim, um papel de fronteira e de desenvolvimento do acesso à informação.

A partir da questão como melhorar o acesso à informação científica e técnica na biblioteca digital, apresentamos uma perspectiva de enquadramento e sinergia entre a Ciência da Informação, a Terminologia e a Engenharia do Conhecimento, para elaborar uma metodologia de trabalho de construção de vocabulários controlados para a informação de especialidade.

\begin{abstract}
Digital special library highlights the need for specialized terminology use and for classification tools that allows establishing a connection of this terminology between specialists and nonspecialists users. Content organization and the terminology to access information constitute a difficulty either for user or information manager because of information amount and variety. Scientific and technical information plays a role of border line and of development on information access.

From the question of how to improve access to technical and scientific information in digital library, we present a frame perspective and synergy between Information Science, Terminology and Knowledge Engineering, to prepare a work methodology for controlled vocabularies of scientific and technical information.
\end{abstract}

\section{Introdução}

Hoje, organizar, tratar, preservar e disponibilizar informação são etapas reais e contínuas por mais distintas que sejam as ferramentas tecnológicas. $\mathrm{O}$ acesso à informação é automático mas o trabalho de bastidores continua a ser humano. $\mathrm{O}$ bibliotecário serve-se de instrumentos que conferem autonomia ao utilizador para este compreender a forma de pesquisa e identificar as suas questóes no eixo temático.

A biblioteca, no desempenho de um papel social de memória e preservação de informação, procura equilibrar o acesso ao conhecimento nos diferentes estádios de desenvolvimento e aprendizagem, pois as competências para simplificar, ordenar, interpretar e reestruturar o aparente caos de informaçâo emergente da elevada complexidade 
da realidade, sobre a qual a ciência se debruça, reforça sem dúvida a capacidade de abstraç̧ão, bem como a inferência e o reconhecimento do significado de inter-relaçôes e interdependências características da realidade reforçam a capacidade de pensamento sistémico (Veríssimo, Ribeiro, 2003:3).

$\mathrm{Na}$ biblioteca digital, a pesquisa em texto livre com recurso ou não a filtros, que restringem o âmbito da pesquisa, vem simplificar o acesso à informação mas também cria muitas vezes resultados de pesquisa complexos.

Sendo a classificação a forma de representar o assunto dos documentos, parecenos que a sugestão de boas práticas para a recuperaçáo de informaçáo começa na consistência do armazenamento dos documentos. Esta coerência assenta na organizaçáo do domínio científico e técnico como o especialista e o utilizador o poderão ver e não como a biblioteca se organiza.

E a questáo que nos surge é sobre os critérios de organizaçáo e de classificaçáo da informação, considerando as características do discurso científico e técnico e a diversidade na língua em especialidade. Como refere Humboldt, the interdependence of thought and speech makes it clear that languages are not so much means of expressing truth that has already been established, as means of discovering truth that was previously unknown. Their diversity is a diversity not of sounds and signs but of ways of looking at the world. ${ }^{1}$

\section{Ciência da Informação - a biblioteca digital especializada}

A biblioteca digital especializada reúne um acervo de informação científica e técnica que tem de estar acessível a um leque variado de utilizadores. A descriçấo, a identificação única e a indexação dos conteúdos permitirá uma selecção mais eficaz e orientada para a necessidade dos utilizadores.

Ao nível da recuperação da informação, a selecção de um tesauro como filtro de pesquisa deverá permitir cruzar diversos vocabulários (entre o documento, o bibliotecário e o utilizador) e criar uma expressão de pesquisa com maior coerência. Consideramos que a qualidade do acesso e recuperação de informação é uma consequência da clareza e exaustividade na classificação e indexação da informação e documentação. A maior dificuldade de recuperaçáo da informação reside, de acordo com Lerat (1995:111), entre le mot clé de l'interrogation, le descripteur autorisé, contrôlé, à contenu de sens stabilisé au sein d'un système documentaire, et les mots du texte lui-même.

Perante a questáo de como melhorar o acesso à informação científica e técnica, parecenos que a utilizaçáo do tesauro, enquanto filtro de pesquisa, garante um enquadramento do vocabulário a usar e um melhor resultado de pesquisa. Esta possibilidade de enquadramento reside na visualizaçâo da intersecçâo de conceitos que permite ao utilizador apreender a terminologia do domínio.

Deste modo, o tesauro tem a funçáo de instrumento de indexaçáo e de pesquisa. E na recuperação de informação, o tesauro é também um serviço de referência digital

\footnotetext{
${ }^{1}$ Wilhelm von Humboldt. Disponível em: http://wuhpnet.googlepages.com/Languagethoughtculture. ppt [Acedido em 27-07-2009]
} 
que realça o papel do bibliotecário enquanto responsável pela organização do conhecimento, pois a mais valia da biblioteca digital não reside nas suas coleç̧óes mas na forma como estas se encontram organizadas e sáo disponibilizadas a todo um conjunto de utilizadores (Borges, 2002:157).

Por outro lado, seguindo a metodologia de construçáo de um tesauro ${ }^{2}$ temos a questão sobre os critérios de classificação solucionada. No entanto, é nesta mesma metodologia que encontramos dúvidas de utilização para a informação de especialidade.

\section{Ciência da Informação \& Terminologia}

A Terminologia é reconhecida como uma disciplina autónoma que integra diversas teorias e metodologias (Costa, 2006:77), ao combinar uma perspectiva linguística, cognitiva e de comunicação da língua em especialidade. Sendo o propósito de comunicação, de forma clara, comum aos diversos contextos sociais, queremos salientar a perspectiva linguística e cognitiva da terminologia numa dada comunidade científica pois objects are assumed to exist and attention shall be focused on how one deals with objects for the purpose of communication (ISO 704:2000:2).

Do ponto de vista linguístico, o termo é uma unidade lexical que representa uma unidade de conhecimento e é usada na comunicação em diversos contextos. Com base na sociolinguística surge a perspectiva da socioterminologia (Gaudin, 2005:81) que se fixe comme l'étude de la circulation des termes en synchronie et en diachronie, ce qui inclut l'analyse et la modélisation des significations et des conceptualisations.

Numa perspectiva cognitiva (Sager, 1990:15), as relaçóes entre conceitos constituem um sistema referencial onde cada unidade terminológica é uma unidade de conhecimento e a terminologia cumpre o papel de permitir a comunicação e a representação deste conhecimento especializado através da definição dos conceitos.

A metodologia para a organização da terminologia pode combinar a abordagem linguística e a conceptual de forma a identificar as relaçóes entre conceitos de acordo com o contexto.

A Ciência da Informação e a Terminologia são ciências pluridisciplinares que interagem a níveis distintos com outras ciências e por isso também entre si. Como refere Cabré (1999:231) existe uma relación recíproca. O trabalho que se desenvolve ao nível da Terminologia não é realizado sem documentação, e uma parte do trabalho que se desenvolve na Ciência da Informação - la relativa a la descripción del contenido de los documentos - no puede realizarse sin terminología. É neste prisma que observamos a prática da Terminologia e a prática da Ciência da Informação.

Para Lerat (1995:107), na Ciência da Informação há uma actividade mais lógica do que linguística na collecte systématique, l'organization, le stockage, la recherche et la diffusion de l'information spécialisée. Dado que a função do gestor de informação é a de analisar o conteúdo dos documentos, de os classificar e de os recuperar, Lerat entende que se trata clairement d'ingénierie de la connaissance e não de engenharia linguística.

\footnotetext{
2 NP 4036:1992, entre outras, que referimos no ponto 3.1.
} 
Por outro lado, refere ainda Cabré (1999:231s), en el trabajo terminológico o terminografía, la documentación sirve para detectar, analizar, clasificar e ilustrar las unidades terminológicas, y también para adquirir competencia cognitiva sobre una materia o verificar informaciones. Para representar o conteúdo dos documentos, a Ciência da Informação tem de sistematizar a terminologia seleccionada e fazer uma escolha - classificando os termos como descritores e não-descritores — de forma a recuperar a informação. Sager (1990:114) refere um princípio indicado por Wüster que entendemos aplicar-se também à gestão de informação - It is impossible to standardize terms in any useful way without previously or at the same time having systematized all relevant concepts.

\subsection{O vocabulário controlado}

Whatever conclusions we draw, whatever inferences we make, will be based on our own understanding of the terminology.

Temmerman (2000:41)

\subsubsection{Problema}

A necessidade de normalizar critérios de elaboração de um tesauro surge com a preocupação de comunicação e partilha de linguagens controladas entre serviços de documentação. Para análise e uso destes princípios que servem de base para uma metodologia de elaboração de um tesauro, seleccionámos as normas que estão disponíveis em português e são usadas na generalidade das bibliotecas.

Todavia, identificámos lacunas nas linhas de orientação da metodologia nas normas NP 4036:1992 [ISO 2788:1986, harmonizada] e NP 3715:1989 [ISO 5964:1985, equivalente] — para a elaboração de vocabulários controlados para a informação de especialidade. Em síntese, focamos três aspectos: $i$. a incoerência na identificação de terminologia na fase de uso e de construção do tesauro, ii. a não identificação da tipologia das relaçôes associativas e iii. a não obrigatoriedade da elaboração da definição.

Considerando que o tesauro tem por base um vocabulário que pode ser considerado como um produto do trabalho terminológico (Mendes, 2008:54), analisámos as semelhanças e diferenças do trabalho que se desenvolve em Ciência da Informação e na Terminologia.

\subsubsection{Metodologia}

A análise do trabalho terminológico concentrou-se na identificação do objectivo e campo de aplicação, etapas de trabalho e definições que constam em duas normas do comité técnico 46 (CT-46) e do comité técnico 37 (CT-37) da ISO-International Standard Organization:

- NP 4036:1992-Documentação. Tesauros monolíngues: directivas para a sua construção $e$ desenvolvimento [CT-46] 
- NP 3715:1989-Documentação. Método para a análise de documentos, determinação do seu conteúdo e selecção de termos de indexação [CT-46]

- ISO 704:2000-Terminology work: principles and methods [CT-37]

- ISO 1087-1:2000-Terminology work: vocabulary. Part 1: theory and application [CT-37]

Presentemente, podemos referir alguma actualização sobre as normas da responsabilidade do CT-46, pois está em desenvolvimento a norma ${ }^{3}$ ISO/CD 25964 1 Information and documentation - thesauri and interoperability with other vocabularies -- Part 1: Thesauri for information retrieval, que faz a revisão das normas ISO 2788:1986 e ISO 5964:1985.

- Objectivo e campo de aplicação

A indexação é a acção que consiste em descrever um documento relativamente ao seu conteúdo, representando esse conteúdo numa linguagem documental (NP 3715:1989:4). Os instrumentos de indexação têm por base o trabalho de selecção e recolha de vocabulário que é caracterizado como um trabalho de organizaçáo de terminologia, ou seja the systematic collection, description, processing and presentation of concepts and their designations (ISO 1087-1:2000:10) e que por sua vez pode ser apresentado sob a forma de bancos de dados, glossários, tesauros ou outras publicaçóes ${ }^{4}$.

A preocupação por uma prática coerente de indexação com base na apresentação e organização de termos preferenciais é o objectivo e campo de aplicação da NP 4036:19925 cujas técnicas para a construção de um tesauro se baseiam em princípios genéricos aplicáveis a todas as áreas do saber. No entanto, refere que um indexador que trabalhe num dominio especifico pode, algumas vezes, ter de se afastar destas recomendaçóes gerais (NP 4036:1992:4).

A norma ISO 704:2000 descreve procedimentos para a formação de termos e para a formulação de definiçôes e apresenta critérios de representação gráfica para as relaçóes entre conceitos, que permitem identificar melhor a base lógica de um sistema conceptual. A ISO 1087-1:2000 complementa a ISO 704:2000 na definição de vocabulário.

- Síntese da análise

Observando as definiçôes de algum vocabulário genérico e relativo ao campo de aplicaçáo das normas NP 4036:1992 e ISO 704:2000, podemos verificar que o termo de indexação se aproxima de designation quanto ao tipo de realidades a que se aplicam. Um termo de indexação não pode ser um símbolo por dificuldade na recuperação de informação.

\footnotetext{
${ }^{3}$ www.iso.org. [acedido em 28.07.2009]. A norma ISO/CD 25964-1 está em desenvolvimento (3103-2009). Aguardamos a sua publicação. No trabalho de investigação em referência (MENDES, 2008) as normas portuguesas são o objecto de análise; no entanto, também a norma ANSI/NISO-Z.39.19.2005 foi observada sobre o tratamento de 'definição' (scope note) e confirmámos a não obrigatoriedade da sua elaboração.

4 "Note: terminological data may be presented in the form of term banks, glossaries, thesauri and other publications" (ISO 1087-1:2000:10).

${ }^{5}$ A versão portuguesa das normas ISO 2788:1986 (=NP 4036:1992) e ISO 5063:1989 (=NP 3715:1989) surge em 1992 e 1989 respectivamente. No entanto, para efeito de análise dos seus conteúdos consideramos as datas indicadas enquanto norma ISO.
} 
Objecto, conceito, designação e definição são termos fundamentais em Terminologia que analisamos em comparação com os termos fundamentais em Ciência da Informação. Os objectos são percepcionados e apreendidos em conceitos, representados em designaçôes e descritos nas definiçóes (ISO 704:2000:vi); podem ter uma natureza material, imaterial e/ou abstracta e podem ser designados através de termos; do mesmo modo os termos de indexaçâo representam conceitos que podem ser relativos a entidades concretas, abstractas ou individuais.

Verificamos também que as relaçóes semânticas que são possíveis de estabelecer entre os conceitos são semelhantes, mas a NP 4036:1992 apresenta outras possibilidades para além das comuns à ISO 704:2000.

Tabela 1 - Relaçóes entre conceitos: NP 4036:1992 e ISO 704:2000

\begin{tabular}{|l|l|}
\hline NP 4036:1992 & ISO 704:2000 \\
\hline relaçáo de equivalência & -- \\
\hline $\begin{array}{l}\text { relaçáo hierárquica } \\
\text { relaçáo genérica } \\
\text { relaçáo partitiva } \\
\text { relaçáo de instância }\end{array}$ & $\begin{array}{l}\text { hierarchical relation } \\
\text { generic relation } \\
\text { partitive relation }\end{array}$ \\
\hline relaçáa associativa & associative relation \\
\hline
\end{tabular}

A relação de equivalência tem em conta a necessidade de fazer uma escolha entre termos de indexação mais representativos que outros, identificando sinónimos e quasisinónimos. Em Terminologia a questão da sinonímia também é analisada mas não resulta num eixo do sistema conceptual ao mesmo nível que as outras relaçóes.

A diferença mais evidente na recolha de terminologia reside na elaboração da definição sugerida na ISO 704:2000 e quase ignorada nas NP 3715:1989 e NP 4036:1992. Esta refere que para o controlo do vocabulário, isto é, para zelar pela coerência de construçáo do tesauro, cada termo de um tesauro está geralmente restrito a um único sentido, aquele que se revele mais eficaz para o sistema de indexação. E deste modo, as relaçóes estabelecidas entre termos constituem-se como suficientes para identificar o sentido do termo.

Contudo, a norma também considera que caso as relaçôes não sejam explícitas, deverá juntar-se uma nota explicativa, mas sem carácter obrigatório (NP 4036:1992: 8). A função da nota explicativa (scope note) é a de identificar a aplicação de um termo de indexação e serve para desambiguação no uso do tesauro e não é obrigatória. Consideramos, todavia, que a nota explicativa não é suficiente para a gestão de informação de especialidade. A definição dos conceitos tem um papel fundamental no raciocínio que está na base do estabelecimento das relaçóes entre conceitos e na elaboração do tesauro. A norma ISO 704:2000 identifica os tipos de definição e os aspectos metodológicos para aplicação da teoria e identificação de critérios de redacção da definição terminológica.

A definiçáo descreve o conceito, e não o termo, através de uma combinação única de características (ISO 704:2000:3) para podermos distinguir um conceito de outro dentro de um sistema conceptual. Ela é elaborada de acordo com a posiçáo que o conceito poderá ocupar no sistema conceptual e, deste modo, identificam-se as 
diferenças através das características ou propriedades dos conceitos no eixo hierárquico e/ou associativo mais próximos.

A norma ISO 704:2000 considera dois tipos de definição: $i$. a definição por intenção ou de compreensão - que identifica o conceito no seu contexto seguido dos traços distintivos; ii. a definição por extensão — que identifica outros conceitos e expande o contexto de aplicação do conceito.

Delimitar, descrever e distinguir são as três acçôes de construção da definição. Definir a estrutura da definição implica a delimitação do domínio e a descrição das características essenciais, que diferenciem os conceitos no sistema conceptual, de acordo com as necessidades do utilizador e do domínio, uma vez que on ne peut pas utiliser de langage scientifique sans définitions (Bessé, 1990:253).

Do mesmo modo que uma biblioteca especializada propóe a organização e difusão da informação de acordo com o domínio, igualmente as teorias e metodologias em Terminologia são equacionadas de acordo com os objectivos e tipologia de conceitos e o domínio em que se enquadram.

Procurando a exaustividade no tratamento da terminologia, propomo-nos fazer uso das orientaçóes da ISO 704:2000 uma vez que o trabalho terminológico acompanha a evolução terminológica científica e técnica. Pelo contrário, a Ciência da Informação preserva a informação, não participa na criação de conteúdos científicos, apenas pode garantir a sua divulgação, preservação e recuperação.

O tesauro é a ferramenta que pode combinar duas funcionalidades: a de vocabulário controlado, para a indexação, e a de guia para auxílio de pesquisa de informaçáo. No contexto da informação científica e técnica, concluímos que os critérios de análise de conteúdo e de identificação de terminologia são a base de trabalho a melhorar nestas normas (CT 46). Por um lado, porque existe a necessidade de definir todos os termos antes de organizar o vocabulário em linguagem de indexação (ao escolher o descritor e o não-descritor). E por outro, sendo a evolução da terminologia científica e técnica uma constante, o tesauro de um dado domínio pode ser uma ferramenta de sistematização da evolução da terminologia e de representação do conhecimento.

\section{Ciência da Informaçáo \& Terminologia \& Engenharia do Conhecimento}

Assistimos, hoje, a uma aparente contradição na pesquisa da informação, pois o acesso digital ao documento electrónico (texto integral) pode oferecer ora mais informaçâo, ora menos informação, do que uma pesquisa orientada por assunto. Esta questão há muito que é debatida em Terminologia e nas ciências afins à representação do conhecimento. $\mathrm{O}$ texto científico e técnico tem por característica não conter toda a informaçáo de forma explícita, embora possa haver variaçóes de acordo com a tipologia da Ciência.

Referimo-nos ao conhecimento implícito e explícito que é um problema na recuperação da informação e, do mesmo modo, um problema na selecção de terminologia. A selecção e recolha automática de terminologia, assim como a indexação automática, não colocam os conceitos/termos no eixo cognitivo. Como conclui Roche (2007:6), saying is not modelling. (...) Understanding text, and then understanding the meaning of terms, requires extra-linguistic knowledge which by definition is not included in the corpus. 
A percepção de um termo, que é o primeiro aspecto referido por Temmerman (2000), está intimamente ligada à teoria da relevância, de Sperber e Wilson (2004), que identifica a comunicaçáo como um processo que envolve inferência na interpretação de um conceito. Deste modo, acentua a capacidade de apreensão, e de representação de conhecimento, resultante do contexto.

A partir do primeiro contacto com a unidade de informação, desenrola-se a compreensão do conceito e/ou da categoria de conceitos que depende de aspectos culturais e socioeconómicos. Como sugere Prado Coelho (2003:4) — todos os conceitos têm pelo menos um sentido documental (civilizacional) e uma dimensão expressiva (cultural).

Esta realidade acentua a necessidade de desenvolvimento de ferramentas de acesso e visualização de informação científica e técnica pois a terminologia, enquanto ponto de acesso à informação, é um instrumento de comunicação entre o utilizador e os sistemas de gestão de informação. Para Lerat (1995:107), ce vocabulaire contrôlé ressemble fort à une terminologie, car les descripteurs du documentaliste sont des dénominations servant de clés d'accès autorisées pour sa recherche, de même que les termes sont des dénominations recommandables pour optimiser la communication spécialisée.

A terminologia de um dado domínio deve, em nosso entender, ser organizada de acordo com as relaçóes estabelecidas entre os conceitos. A Norma ISO 704:2000 estipula que um sistema conceptual serve para: modelizar estruturas conceptuais com base no conhecimento especializado de um domínio; clarificar as relações entre conceitos; constituir a base para uma terminologia uniforme e normalizada; facilitar a análise comparativa de conceitos e designaçóes entre línguas e facilitar a escrita de definiçôes (ISO 704:2000:12).

\subsection{Sistemas de representaçáo de conhecimento}

A ciência não é a história da natureza nem acumulação de factos; é a arquitectura de um quadro do mundo

Harré (1988:27)

A preocupação de criar a arquitectura do conhecimento é comum à Terminologia, à Ciência da Informação e à Engenharia do Conhecimento, porque são ciências pluridisciplinares que estabelecem diferentes pontes de comunicação.

Identificar as relaçôes entre conceitos é uma forma de classificar, pois as classificaçôes são elementos geográficos mentais e só elas nos permitem orientar-nos no mundo à nossa volta, estabelecer hábitos, semelhanças e diferenças, reconhecer os lugares, os espaços, os seres, os acontecimentos; ordená-los, agrupá-los, aproximá-los uns dos outros, mantê-los em conjunto ou afastá-los irremediavelmente (Pombo, 1998:1).

Organizar conhecimento é, por isso, uma necessidade de compreensão de um contexto que se realiza através da associação e distinção de ideias, de conceitos ${ }^{6}$.

\footnotetext{
6 "A actividade analítica que se aplica às associaçôes é a classificação. Fora do discurso (plano sintagmático), as unidades que têm entre si qualquer coisa de comum associam-se na memória e formam assim grupos em que existem relaçóes diversas [Saussure]" (Barthes, 2007:56).
} 
Verificamos que a representação do conhecimento tem na sua base dois tipos de classificaçôes que são consideradas essenciais em Filosofia ${ }^{7}$ : $i$. a classificação baseada na presença ou ausência de uma determinada propriedade e ii. a classificação baseada numa propriedade caracterizada como diferença específica.

A definição é o elemento, por um lado, que pode traduzir a presença ou ausência de uma propriedade e, por outro, são estas propriedades essenciais que permitem estabelecer ligaçóes específicas entre conceitos.

O trabalho que é desenvolvido em Terminologia assenta na sistematização das relaçôes entre conceito e termo através da identificação de características do conceito para, em primeiro lugar, distingui-lo e separá-lo dos outros conceitos e, em seguida, posicioná-lo no sistema conceptual (Costa, 2006:80). A estrutura do sistema conceptual corresponde, entâo, às relaçóes que se estabelecem entre conceitos que podem ser, como vimos no início, relaçóes hierárquicas (genéricas e partitivas) e relaçóes associativas.

De entre os instrumentos de representação de conhecimento focamos o tesauro e a ontologia. Estabelecer as diferenças entre tesauro e ontologia é um tema muito debatido entre os domínios da Ciência da Linguagem, da Terminologia, da Ciência da Informação, da Filosofia e da Inteligência Artificial.

Escolhemos uma definição de ontologia que consideramos mais próxima para a análise de sistemas conceptuais a que nos propomos (Roche, 2005:57):

Définie pour un objectif donné et un domaine particulier, une ontologie est pour l'ingénierie des connaissances une représentation d'une modélisation d'un domaine partagée par une communauté d'acteurs. Object informatique défini à l'aide d'un formalisme de représentation, elle se compose principalement d'un ensemble de concepts définis en compréhension, de relations et de propriétés logiques.

A estrutura e conteúdo de um tesauro, isto é de um vocabulário controlado e organizado, serve a prática de indexação. Uma ontologia poderá servir para indexação se esse for o propósito da sua construção, pois uma ontologia é definida para um domínio em particular e para um determinado objectivo (Roche, 2005:57); no mesmo sentido, os critérios de construção da ontologia serão também os critérios de avaliação da sua qualidade - we can assess the quality of our ontology only by using it in applications for which we designed it (Noy, McGuiness, 2001:23).

Considerando a ontologia uma estrutura aplicada à gestão de informação que permite a representação da informação segundo as relaçóes estabelecidas ${ }^{8}$, poderemos ter esta mesma estrutura adaptada às necessidades da gestão de informação de especialidade.

\footnotetext{
7 Perelman, 1963 apud POMBO (1998:6)

${ }^{8}$ A par da referida revisão das normas ISO 2788 e ISO 5964 referimos também este documento SKOSSimple knowledge organization system primer (working draft), disponibilizado a 15 de Junho de 2009. E que provides a model for expressing the basic structure and content of concept schemes such as thesauri, classification schemes, subject heading lists, taxonomies, folksonomies, and other similar types of controlled vocabulary. Disponível em: http://www.w3.org/TR/2009/WD-skos-primer-20090615/ [acedido em 26-06-2009].
} 
Perante a questão de como melhorar o acesso à informaçâo científica e técnica na biblioteca digital, sugerimos a representação da informação e do conhecimento num mapa conceptual, que oferece uma visão do mundo de um dado domínio do saber, organizado com base nas relaçóes entre conceitos.

\section{Conclusóes}

Na Ciência da Informação, o bibliotecário desempenha um papel de mediação entre a informação e os utilizadores. Neste contexto, de informação de especialidade, constatámos que existe um elo de complementaridade entre a organização de terminologia, em Terminologia, e a gestão de informação, na Ciência da Informação, porquanto a terminologia é o meio de comunicação entre o utilizador e a informação, entre o bibliotecário e o utilizador e entre o bibliotecário e a informação.

Pelo trabalho desenvolvido em cada uma das ciências existe também uma relação de reciprocidade na necessidade de recorrer à documentação e à terminologia. Se por um lado, o trabalho terminológico incide na organização e na representação do conhecimento no acompanhamento da investigação tecnológica e científica, por outro, na Ciência da Informação, a gestão da informaçáo consiste na representação do conteúdo dos documentos através de terminologia com o objectivo de preservar e garantir a divulgação e a recuperação da informação.

A representação de informação e de conhecimento é ainda comum à Engenharia do Conhecimento onde as ferramentas de gestão de terminologia e de organização hipertextual, oferecendo dinamismo de pesquisa, possibilitam uma aproximação ao nosso modelo conceptual de representação do conhecimento. A vantagem da representação das relaçôes ontológicas reside na orientação que se oferece ao utilizador, e ao indexador, das linhas de ligação entre termos, permitindo melhor apreensão da informação e compreensão dos conceitos.

A nossa perspectiva de elaboraçáo do vocabulário controlado de e para a informação científica e técnica, num dado domínio, enquadra-se na necessidade de reunir critérios e argumentos de sistematização de terminologia que permitam oferecer um quadro lógico da organização da informação no contexto da biblioteca digital especializada.

\section{Referências bibliográficas}

BARTHES, Roland (2007) - Elementos de semiologia. Lisboa : Edições 70. ISBN 978-9724413-86-0.

BESSÉ, Bruno de (1990) - La définition terminologique. In CHAURAUD, Jacques; MAZIÈRE, Francine, ed. — La definition. Paris : Libraririe Larousse. ISBN 2-03-7600518. p. 252-261.

BORGES, Maria Manuel (2002) - De Alexandria a Xanadu. Coimbra : Quarteto Editora. ISBN 972-8535-80-5.

CABRÉ, Teresa (1999) - La terminologia : representación y comunicación. Elementos para una teoria de base comunicativa y otros artículos. Barcelona : Universidade Pompeu Fabra. 
COSTA, Rute (2006) - Plurality of theoretical approaches to terminology. In PICHT, Herbert, ed. - Modern approaches to terminological theories and applications. Bern: Peter Lang. ISBN 3-03911-156-6. p. 77-89.

GAUDIN, François (2005) - La socioterminologie. Langages. Paris : Larousse. ISBN 203577079-3. No 157 , p. 80-92.

HARRÉ, Rom (1988) - As filosofias da ciência. Lisboa : Edições 70

ISO 1087-1:2000 - Terminology work : Vocabulary. Part 1: Theory and application. Genève: ISO, 2000.

ISO 704:2000 - Terminology work. Principles and methods. Genève: ISO, 2000.

LERAT, Pierre (1995) - Les langues specialisées. Paris : PUF. ISBN 2-13-046602-8.

MENDES, Olga Bessa (2008) - A gestão de informação na biblioteca especializada - as linhas de fronteira da pesquisa de informaçâa. Tese de mestrado. Lisboa : Universidade Nova de Lisboa.

NP 3715:1989 - Documentação. Método para a análise de documentos, determinaçáo do seu conteúdo e selecçáo de termos de indexaçáo. Lisboa : IPQ, 1989. [corresponde ISO 5963].

NP 4036:1992 - Documentaçáo. Tesauros monolingues : directivas para a sua construção e desenvolvimento. Lisboa : IPQ, 1993. [harmoniza ISO 2788(1986)].

NOY, Natalya; McGuinness, Deborah L. (2001) - Ontology development 101: a guide to creating your first ontology [em linha]. [Acedido em 10-02-2008]. Disponível na www:<URL:http://prote ge.stanford.edu/publications/ontology_development/ontology 101 . pdf $>$.

POMBO, Olga (1998) - Da Classificaçáo dos Seres à Classificaçáo dos Saberes. Leituras. Revista da Biblioteca Nacional de Lisboa. ISSN 0873-7045. No 2, Primavera, p. 19-33.

PRADO COELHO, Eduardo (2003) - Para uma história da conectividade [em linha]. [Acedido em 20-12-2007]. Disponível na www: <URL : www.ciberscopio .net>.

ROCHE, Christophe (2007) - Saying is not modelling. In ICEIS, 9, Funchal, 2007 - NLPCSNatural Language Processing and Cognitive Science. p. 47-56.

ROCHE, Christophe (2005) - Terminologie et ontologie. Langages. Paris : Larousse. ISBN 203-577079-3. No 157, p. 48-62.

ROCHE, Christophe (2008) - Quelle terminologie pour les sociétés de l'information? Lexique, dictionnaire et connaissance dans une société multilingue, Cahiers de linguistique, 2007 [2008]. ISSN 0771-6524. ISBN 978-2-930481-52-4. Vol. 43/1, pp. 139 - 160.

SAGER, Juan C. (1990) - A practical course in terminology processing. Amsterdam : John Benjamins. ISBN 9789027220776.

SPERBER, Dan; WILSON, Deirdre (2004) - Relevance Theory [em linha]. [Acedido em 15-052008]. Disponível na www: <URL:http://www.dan.sperber.com/relevance_theory.htm>.

TEMMERMAN, Rita (2000) - Towards new ways of terminology description. The sociocognitive approach. Amsterdam-Philadelphia : John Benjamins. ISBN 90-2722326-2.

VERÍSSIMO, António; RIBEIRO, Rui (2003) - Educação em ciências e cidadania: porquê, onde e como [em linha]. [Acedido em 20-12-2007]. Disponível na www : <URL : www. ciberscopio.net>. 